\title{
Microstructure and Coercivity of Granular Nanocomposite FePt-Ag Multilayer Films
}

\author{
S. C. Chen ${ }^{1}$, P. C. $\mathrm{Kuo}^{2}$, A. C. $\mathrm{Sun}^{2}$, C. Y. $\mathrm{Chou}^{2}$, Y. H. Fang ${ }^{2}$, and S. Y. Kuo ${ }^{3}$ \\ ${ }^{1}$ Department of Materials Engineering, Ming Chi University of Technology, Taipei 243, Taiwan, \\ R.O.C., and Center for Nanostorage Research, National Taiwan University, Taipei 106, Taiwan, R.O.C. \\ ${ }^{2}$ Institute of Materials Science and Engineering and Center for Nanostorage \\ Research, National Taiwan University, Taipei 106, Taiwan, R.O.C. \\ ${ }^{3}$ Department of Civil Engineering, De Lin Institute of Technology, Taipei 236, Taiwan, R.O.C.
}

\begin{abstract}
The face-centered-tetragonal granular $\mathrm{L1}_{0} \mathrm{FePt}$ nanoparticles with large in-plane coercivity (Hc//) of about 3923 Oe can be achieved by an Ag-capped layer of 5-nm thickness deposited onto the FePt magnetic layer, with thickness of $20 \mathrm{~nm}$, after annealing at $400{ }^{\circ} \mathrm{C}$ for $30 \mathrm{~min}$. The perpendicular coercivity $\left(\mathrm{Hc}_{\perp}\right)$ of the films is increased by increasing the annealing temperature $\left(T_{s}\right)$, and the $\mathrm{Hc} \mathrm{c}_{\perp}$ value is about equal to the $\mathrm{Hc} / /$ value when the annealing temperature is increased to $600{ }^{\circ} \mathrm{C}$. TEM-energy disperse spectrum analysis reveals that the Ag mainly distributed at the grain boundary of FePt and results in the isolation of the FePt grains as well as the increase of the grain boundary energy, which will enhance coercivity and change the preferred orientation of the FePt film.
\end{abstract}

Index Terms-Ag-capped layer, coercivity, FePt-Ag multilayer films, magnetron sputtering.

\section{INTRODUCTION}

$\mathbf{R}$ ECENTLY, FePt nanograins have attracted much attention for their potential applications for high-density magnetic recording media [1], because of high-magnetocrystalline anisotropy $\left(\mathrm{Ku} \sim 7 \times 10^{7} \mathrm{erg} / \mathrm{cm}^{3}\right)$ of the orderd $L 1_{0}$ phase. In general, the formation of the $L 1_{0} \mathrm{FePt}$ phase requires a heat treatment at a higher temperature around $600^{\circ} \mathrm{C}$ [2], [3], which results in the grain growth.

The grain size must be reduced to below $10 \mathrm{~nm}$ for high-density magnetic recording media applications. Therefore, high-coercivity materials consisting of the ordered $L 1_{0} \mathrm{FePt}$ phase dispersed in nonmagnetic matrices to refine grain sizes of $\mathrm{FePt}$ have been reported in FePt-C [4], $\mathrm{FePt}-\mathrm{SiO}_{2}$ [5], and $\mathrm{FePtCr}-\mathrm{Si}_{3} \mathrm{~N}_{4}$ [6] thin films. Current studies have been focused on decreasing the energy barrier of phase transformation of FePt from an fccdisordered phase to an fct-ordered phase. Several works on the lowering of ordering temperature and the enhanced coercivity of FePt films have been reported, such as doping a third element [7]-[9] or introducing an underlayer [10]-[13] and capped layer [14], [15] to the FePt films.

An $\mathrm{Ag}$ underlayer is found to be effective in reducing the FePt ordering temperature [10], [11]. The Ag is immiscible with either $\mathrm{Fe}$ or Pt. Instead, it tends to segregate at the grain boundary of FePt [15] and increases the grain boundary energy, which can change the preferred orientation of the FePt film [16]. However, there is still no direct evidence to confirm the exact position of the $\mathrm{Ag}$ in the FePt layer. In this paper, the TEM-energy disperse spectrum (EDS) is used to analyze the $\mathrm{Ag}$ distribution in the FePt layer. The microstructures, magnetic properties, and preferred orientation of the FePt layer of the granular nanocomposite $\mathrm{MgO}-\mathrm{FePt}-\mathrm{Ag}$ multilayer films are also investigated.

Digital Object Identifier 10.1109/TMAG.2005.854703

\section{EXPERIMENT}

The $\mathrm{MgO}$ underlayer of 5-nm thickness is deposited onto naturally oxidized $\mathrm{Si}(100)$ substrates by rf magnetron sputtering at an ambient temperature under an Ar pressure of 10 mtorr. The FePt magnetic layer with a thickness of $20 \mathrm{~nm}$ and an Ag-capped layer of 5-nm thickness are deposited subsequently by dc magnetron sputtering onto the $\mathrm{MgO}$ underlayer. The as-deposited films are annealed at $400{ }^{\circ} \mathrm{C}, 500{ }^{\circ} \mathrm{C}$, and $600{ }^{\circ} \mathrm{C}$ for $30 \mathrm{~min}$ in vacuum higher than $5 \times 10^{-7}$ torr. The composition of the FePt film determined by X-ray EDS is $\mathrm{Fe}_{50.2} \mathrm{Pt}_{49.8}$. The microstructures of the film are investigated by a Philips Tecnai F30 field emission gun (FEG) TEM and by an X-ray diffractometer (XRD) with $\mathrm{Cu}-\mathrm{K}_{\alpha}$ radiation. Compositions of the films are determined by EDS and the depth profiles of elements in the film are analyzed by Auger electron spectroscopy (AES). The magnetic properties of the films are measured using a vibrating sample magnetometer (VSM) at room temperature.

\section{RESUlTS AND DISCUSSION}

Fig. 1 shows the in-plane coercivity and perpendicular coercivity of $\mathrm{MgO} 5 \mathrm{~nm}-\mathrm{FePt} 20 \mathrm{~nm}-\mathrm{Ag} 5 \mathrm{~nm}$ multilayer films as a function of the annealing temperature. It is found that a large $\mathrm{Hc} / /$ value of about 3923 Oe can be obtained after annealing at $400{ }^{\circ} \mathrm{C}$. Compared with the reports of Sellmyer et al. [17] and Kuo et al. [18], an $\mathrm{Hc}$ // value of only 1500-3000 Oe is obtained by annealing at the same temperature for pure FePt films. On the other hand, the $\mathrm{Hc}_{\perp}$ value of the films is increased by increasing the annealing temperature, and the $\mathrm{Hc}_{\perp}$ value is about equal to the $\mathrm{Hc}_{/}$value when the annealing temperature is increased to $600^{\circ} \mathrm{C}$. This indicates that the preferred orientation of the FePt films will be changed from (111) plane to random as the annealing temperature increases from $400^{\circ} \mathrm{C}$ to $600^{\circ} \mathrm{C}$.

Fig. 2 shows the XRD patterns of the $\mathrm{MgO} 5 \mathrm{~nm}-\mathrm{FePt}$ $20 \mathrm{~nm}-\mathrm{Ag} 5 \mathrm{~nm}$ multilayer films after annealing at various temperatures. It is found that the preferred orientation of the 


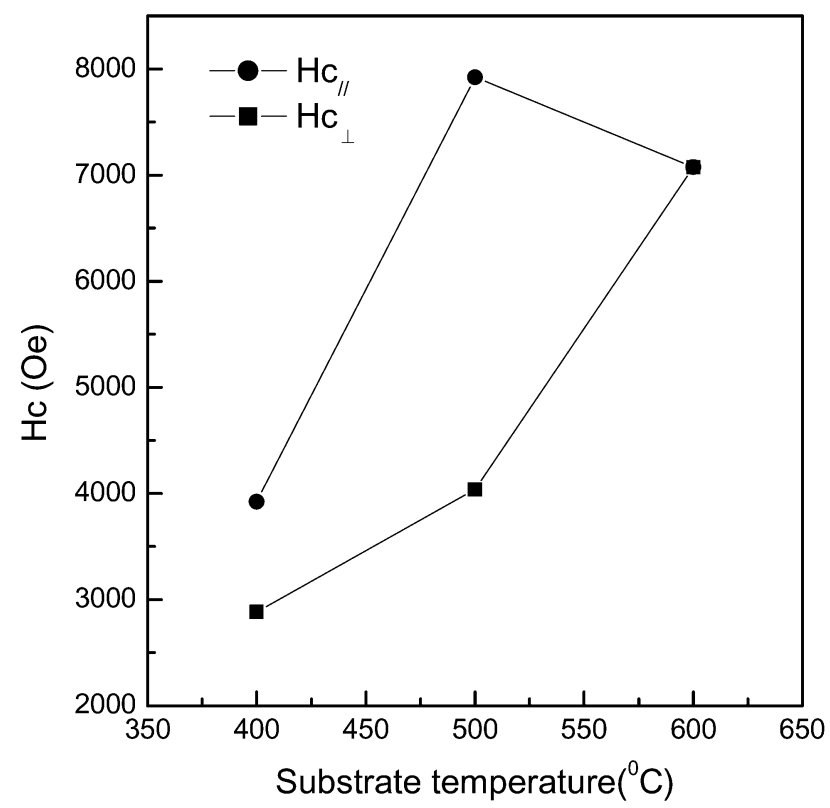

Fig. 1. In-plane coercivity and perpendicular coercivity of $\mathrm{MgO} 5 \mathrm{~nm}-\mathrm{FePt}$ $20 \mathrm{~nm}-\mathrm{Ag} 5 \mathrm{~nm}$ multilayer films as a function of annealing temperature.

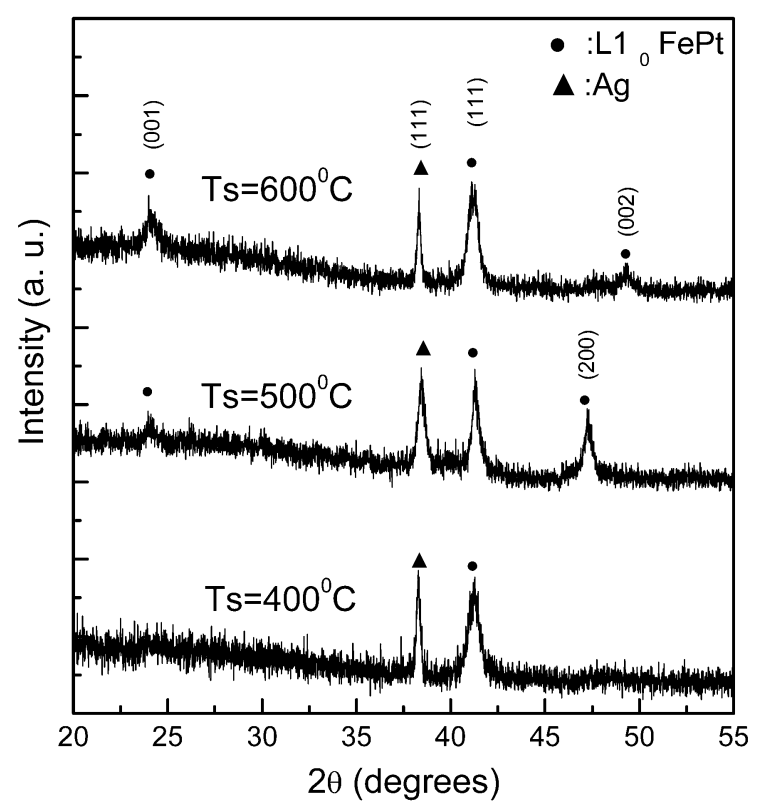

Fig. 2. XRD patterns of the various annealed $\mathrm{MgO} 5 \mathrm{~nm}-\mathrm{FePt} 20 \mathrm{~nm}-\mathrm{Ag} 5 \mathrm{~nm}$ multilayer films. Annealing temperatures are $400^{\circ} \mathrm{C}, 500^{\circ} \mathrm{C}$, and $600^{\circ} \mathrm{C}$.

FePt films is (111) after annealing at $400{ }^{\circ} \mathrm{C}$ and $500{ }^{\circ} \mathrm{C}$. As the annealing temperature increases to $600{ }^{\circ} \mathrm{C}$, the (001) and (002) peaks of the FePt films are enhanced. However, the intensity of the (111) peak of the FePt films almost keeps constant. This means that the preferred orientation of the FePt film will change from the (111) plane to random when the annealing temperature is increased from $400{ }^{\circ} \mathrm{C}$ to $600{ }^{\circ} \mathrm{C}$, which is consistent with the measurement of the coercivities in Fig. 1.

Fig. 3(a) is a TEM bright field image for the $\mathrm{MgO} 5 \mathrm{~nm}-\mathrm{FePt}$ $20 \mathrm{~nm}-\mathrm{Ag} 5 \mathrm{~nm}$ multilayer films which annealed at $600{ }^{\circ} \mathrm{C}$ for $30 \mathrm{~min}$. The TEM image of the film shows a granular structure, and its grain size is about $24 \mathrm{~nm}$. Fig. 3(b) shows the high-resolution TEM lattice image of the enclosed area of Fig. 3(a). In order to understand the exact position of $\mathrm{Ag}$ atoms in the $\mathrm{FePt}$

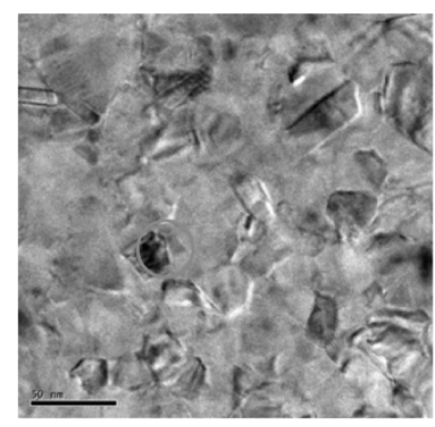

(a)

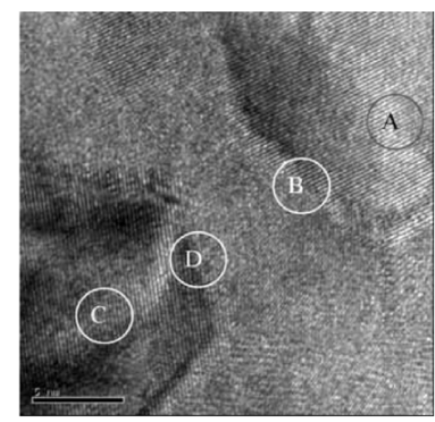

(b)
Fig. 3. (a) TEM bright field image of the $\mathrm{MgO} 5 \mathrm{~nm}-\mathrm{FePt} 20 \mathrm{~nm}-\mathrm{Ag} 5 \mathrm{~nm}$ multilayer films which annealed at $600^{\circ} \mathrm{C}$ for $30 \mathrm{~min}$. (b) High-resolution TEM lattice image of the enclosed area of Fig. 3(a).
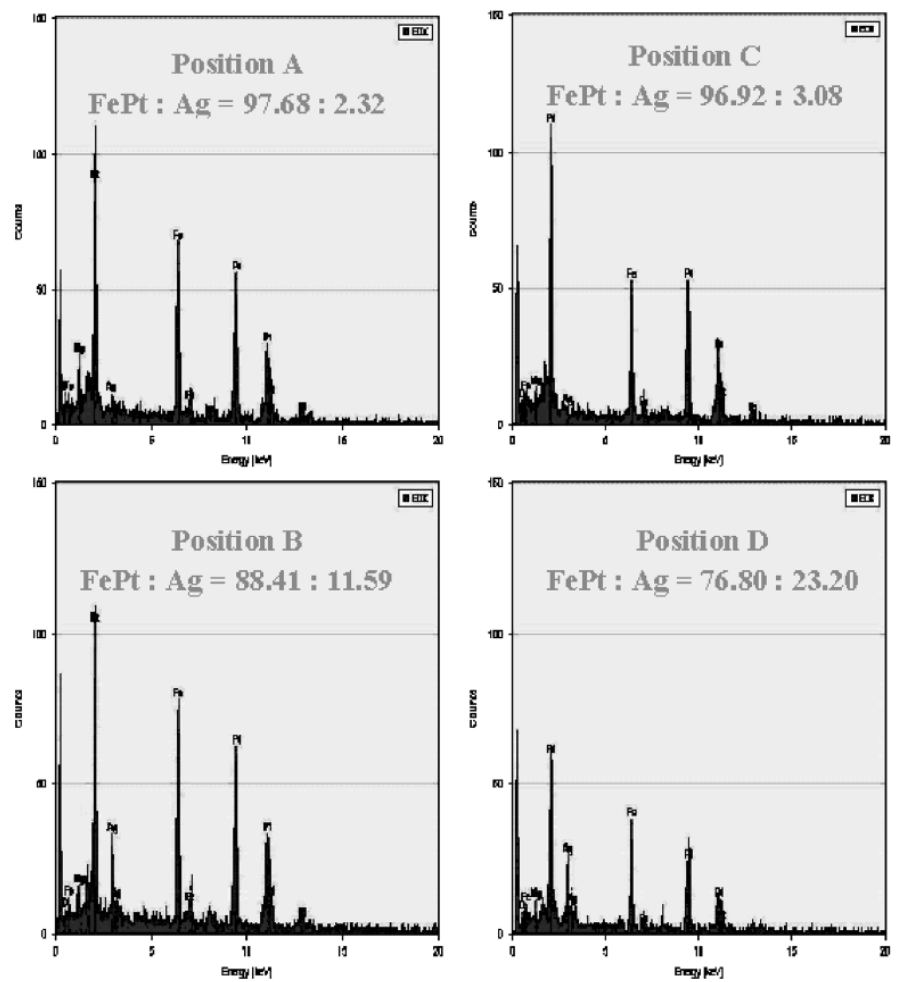

Fig. 4. Ag contents of the enclosed areas of A (inner grain), B (grain boundary), C (inner grain), and D (grain boundary), illustrated in the image of Fig. 3(b).

layer, the TEM-EDS is used to analyze the $\mathrm{Ag}$ contents of the enclosed areas of A (inner grain), B(grain boundary), C(inner grain), and $\mathrm{D}$ (grain boundary), which are illustrated in the lattice image of Fig. 3(b). As shown in Fig. 4, the Ag contents of the enclosed areas of A, B, C, and D are determined to be 2.32, 11.59, 3.08 , and 23.20 at.\%, respectively. The TEM-EDS datas reveals that the $\mathrm{Ag}$ atoms in the $\mathrm{FePt}$ magnetic layer mainly distribute at the grain boundary and result in the isolation of the FePt grains as well as the increase of the grain boundary energy. This will reduce grain size, enhance coercivity, and change the preferred orientation of the FePt film. Therefore, as shown in Fig. 1, the $L 1_{0} \mathrm{FePt}$ nanoparticles with a large in-plane coercivity of about 3923 Oe can be obtained by annealing at a low temperature of $400{ }^{\circ} \mathrm{C}$ for the $\mathrm{MgO} 5 \mathrm{~nm}-\mathrm{FePt} 20 \mathrm{~nm}-\mathrm{Ag} 5 \mathrm{~nm}$ multilayer films. Furthermore, the perpendicular coercivity of the films increases with increasing the annealing temperature, and the $\mathrm{Hc}_{\perp}$ 
value is almost equal to the $\mathrm{Hc} / /$ value as the annealing temperature is increased to $600{ }^{\circ} \mathrm{C}$. This indicates the preferred orientation of the FePt films will change from the (111) plane to random as the annealing temperature increases from $400{ }^{\circ} \mathrm{C}$ to $600^{\circ} \mathrm{C}$, which is confirmed by XRD measurement, as shown in Fig. 2. This result is also ascribed to the $\mathrm{Ag}$ atoms distributed at the grain boundary of FePt to increase the grain boundary energy; hence, it changes the preferred orientation of the FePt films. Similarly, Yuan et al. [14] reported that an Au capped layer on FePt film can largely enhance coercivity, which is also due to the diffusion of $\mathrm{Au}$ into the grain boundary of the FePt layer.

\section{CONCLUSION}

The TEM-EDS analysis results reveal that the Ag mainly distributed at the grain boundary of FePt, which will hinder the grain growth, enhance coercivity, and change the preferred orientation of FePt film. The granular $L 1_{0} \mathrm{FePt}$ nanoparticles with a large in-plane coercivity of about 3923 Oe can be obtained from $\mathrm{MgO} 5 \mathrm{~nm}-\mathrm{FePt} 20 \mathrm{~nm}-\mathrm{Ag} 5 \mathrm{~nm}$ multilayer films after annealing at a low temperature of $400{ }^{\circ} \mathrm{C}$ for $30 \mathrm{~min}$.

\section{ACKNOWLEDGMENT}

This work was supported in part by the National Science Council under Grant NSC 93-2216-E-002-023 and by the Ministry of Economic Affairs, Taiwan, R.O.C., under Grant 93-EC-17-A-08-S1-0006.

\section{REFERENCES}

[1] D. Weller, A. Moser, L. Folks, M. E. Best, W. Lee, M. F. Toney, M. Schwickert, J.-U. Thiele, and M. F. Doerner, "High Ku materials approach to 100 Gbits/in" ${ }^{2}$, IEEE Trans. Magn., vol. 36, no. 1, pp. 10-15, Jan. 2000.

[2] T. Suzuki and K. Ouchi, "Sputter-deposited (Fe-Pt)-MgO composite films for perpendicular recording media," IEEE Trans. Magn., vol. 37, no. 2, pp. 1283-1285, Mar. 2001.

[3] P. C. Kuo, S. C. Chen, Y. D. Yao, A. C. Sun, and C. C. Chiang, "Microstructure and magnetic properties of nanocomposite FePtCr-SiN thin films," J. Appl. Phys., vol. 91, pp. 8638-8640, 2002.
[4] J. A. Christodoulides, Y. Huang, Y. Zhang, G. C. Hadjipanayis, I. Panagiotopoulos, and D. Niarchos, "CoPt and FePt thin films for high density recording media,” J. Appl. Phys., vol. 87, pp. 6938-6940, 2000.

[5] C. P. Luo, S. H. Liou, and D. J. Sellmyer, "FePt:SiO 2 granular thin film for high density magnetic recording," J. Appl. Phys., vol. 87, pp. 6941-6943, 2000.

[6] S. C. Chen, P. C. Kuo, A. C. Sun, C. T. Lie, and C. C. Chiang, "Effects of $\mathrm{Cr}$ and $\mathrm{SiN}$ contents on the microstructure and magnetic grain interactions of nanocomposite FePtCr-SiN thin films," IEEE Trans. Magn., vol. 39, no. 2, pp. 584-589, Jan. 2003.

[7] T. Maeda, T. Kai, A. Kikitsu, T. Nagase, and J.-i. Akiyama, "Reduction of ordering temperature of an FePt-ordered alloy by addition of $\mathrm{Cu}$," Appl. Phys. Lett., vol. 80, pp. 2147-2149, 2002.

[8] S. S. Kang, D. E. Nikles, and J. W. Harrell, "Synthesis, chemical ordering, and magnetic properties of self-assembled FePt-Ag nanoparticles," J. Appl. Phys., vol. 93, pp. 7178-7180, 2003.

[9] H. Y. Wang, W. H. Mao, X. K. Ma, H. Y. Zhang, Y. B. Chen, Y. J. He, and E. Y. Jiang, "Improvement in hard magnetic properties of FePt films by N addition," J. Appl. Phys., vol. 95, pp. 2564-2568, 2004.

[10] Y. N. Hsu, S. Jeong, D. E. Laughlin, and D. N. Lambeth, "Effects of Ag underlayers on the microstructure and magnetic properties of epitaxial FePt thin films," J. Appl. Phys., vol. 89, pp. 7068-7070, 2001.

[11] X.-H. Xu, H.-S. Wu, F. Wang, and X.-L. Li, "Structure and magnetic properties of FePt and FePt/Ag thin films deposited by magnetron sputtering," Thin Solid Films, vol. 472, pp. 222-226, 2005.

[12] C.-H. Lai, C.-H. Yang, C. C. Chiang, T. Balaji, and T. K. Tseng, "Dynamic stress-induced low-temperature ordering of FePt," Appl. Phys. Lett., vol. 85, pp. 4430-4432, 2004.

[13] S. C. Chen, P. C. Kuo, S. T. Kuo, A. C. Sun, C. Y. Chou, and Y. H. Fang, "Improvement in hard magnetic properties of FePt films by introduction of Ti underlayer," IEEE Trans. Magn., vol. 41, no. 2, pp. 915-917, Feb. 2005.

[14] F. T. Yuan, S. K. Chen, W. C. Chang, and L. Horng, "Effect of Au cap layer on the magnetic properties and the microstructure for FePt thin films," Appl. Phys. Lett., vol. 85, pp. 3163-3165, 2004.

[15] Z. L. Zhao, J. Ding, K. Inaba, J. S. Chen, and J. P. Wang, "Promotion of $L 1_{0}$ ordered phase transformation by the Ag top layer on FePt thin films," Appl. Phys. Lett., vol. 83, pp. 2196-2198, 2003.

[16] Y. Z. Zhou, J. S. Chen, G. M. Chow, and J. P. Wang, "Structure and magnetic properties of in-plane oriented FePt-Ag nanocomposites," $J$. Appl. Phys., vol. 93, pp. 7577-7579, 2003.

[17] M. L. Yan, N. Powers, and D. J. Sellmyer, "Highly oriented nonepitaxially grown L1 0 FePt films," J. Appl. Phys., vol. 93, pp. 8292-8294, 2003.

[18] C.-M. Kuo, P. C. Kuo, and H.-C. Wu, "Microstructure and magnetic properties of $\mathrm{Fe}_{100-x} \mathrm{Pt}_{x}$ alloy films," J. Appl. Phys., vol. 85, pp. 2264-2269, 1999.

Manuscript received February 7, 2005; revised April 1, 2005. 